\title{
Study on the Translation of Chinese Culture - loaded Words from the Perspective of Ecological Translation
}

\author{
Youya Zhou
}

Nanchang Institute of Technology, Nanchang, 330099

\begin{abstract}
Keywords: Chinese culture loaded words; Ecological translation; Three - dimensional conversion method
\end{abstract}

\begin{abstract}
In the context of globalization, the exchanges between the various ethnic groups in the world are becoming more and more frequent, but at the same time, the global trend of language and culture is becoming more and more obvious. In order to maintain the balance of the global language and cultural ecosystem, the weak culture should strengthen the external propaganda, and the ecological translation of the Chinese culture-loaded words is an effective means, because the cultural load words carry the cultural information which embodies the national characteristics. The ecological translation of Chinese cultural load words could mainly do from two aspects: to improve the Chinese culture load words translation of the ecological environment and enhance the quality of the translator. The ecological translation of Chinese cultural load words in the context of globalization is conducive to the external transmission of Chinese traditional culture, but also to maintain the identity of Chinese and its culture in the world language and cultural ecosystem, and enhance China and the world mutual understanding between other countries or regions, to promote the pluralistic coexistence of the world language culture and the overall balance of the global language and culture ecosystem.
\end{abstract}

\section{Introduction}

With the integration of the world economy, the exchanges between the various ethnic groups in the world are becoming more and more frequent. In this context, China urgently needs to carry forward its own cultural traditions and let the world pay more attention to Chinese culture. While the international conference and the two sessions of China and other Chinese and foreign journalists will give us a lot of opportunities to spread the Chinese culture. Speakers at the meeting often use the Chinese vocabulary to introduce China's foreign policy, international and domestic situation and problems, and the future development. Foreign journalists who are invited to attend the reception are all very thorough observation of the diplomatic analysis of China's internal affairs, but the understanding of Chinese culture may be not comprehensive. China's cultural load words absorbed the essence of the five thousand years of historical civilization, at the same time, but also contains the new words with the times. The translation of such cultural-loaded words is accurate and timely to convey primitive information, which gives the interpreter a lot of difficulties and challenges. If the translator does not have an accurate and timely understanding of Chinese culture and is not aware of the culture of the country, it is easy to misinterpreted, which will influence foreign journalists' understanding the information we want to convey. Therefore, it is of great practical significance and practical significance to study the English translation of Chinese culture, which is rich in national cultural information, that is, cultural load words, translated into other languages, conducive to foreign exchange of culture.

\section{The Present Situation of Translation of Chinese Culture - Loaded Words}

As a result of the difference between Chinese and foreign lifestyles and ideological aspects, some Chinese cultural load words have appeared the vacancy phenomenonin the English translation, that is, the differences between Chinese and foreign cultures have caused the difficulty of translation of Chinese culture-loaded words, hindering the exchange and development of Chinese and foreign.

With the development of China's economic strength and comprehensive national strength, the 
interest and concern of Chinese culture in China has been increasing, and a "China fever" and "Chinese fever" have been set off, which greatly promoted the Chinese culture English translation and external transmission. However, relative to the English translation of English language culture and its influence in China, the English translation status of Chinese culture loaded word is still to be improved in order to achieve the cultural input and output balance. The following is an analysis of the status quo of some Chinese culture-loaded words.

For example, the Chinese traditional meal of"dumpling", many translation versions are only translated as "dumpling", so many foreign readers only see it as a "dumpling" similar to the Western stuffing dough, while ignoring its cultural connotation, that is, its carrying the meaning of "festive, reunion" in the festival, especially in the Spring Festival, if it is translated as "Jiaozi", which both retain the cultural significance, but also attract more foreign readers interest in this Chinese food. Another example is that the Chinese society is now very popular with"naked official" word, referring to the officials whose huge amount of property are moved abroad, and his wife and children are sent abroad to settle or permanent residence, there are attempts to corrupt and then absconded. Many of which are translated into "officials without family burden" or "offi-cials with family abroad", the former is clearly not in line with the true meaning of the "naked officer", while the latter only partially expresses the meaning of "naked officials".

\section{The Translation of Chinese Culture-Loaded Words from the Perspective of Ecological Translation}

In order to obtain the best translation, the choice of three-dimensional adaptive conversion is the most important theoretical point of view in ecological translation. As we all know, interpreting, especially important national conference interpreters, is more specific than ordinary translation, while the universality of 3D transformation makes it an effective translation method in conference interpreting. So we can illustrate them from three dimensions, respectively.

Language Dimension Adaptive Selection Conversion. The adaptive transformation of language dimension refers to the translator's choice of language in the process of translation. Nida and Taber argue that each language has its own characteristics, and that every successful translator responds to the characteristics of each language in the process of translation and does not force the characteristics of a language to set aside in another language, on the contrary, it will be the unique expression of making the original adjustment for the original structure to adapt to the target language.

For example, the Chinese sentence is often repeated in order to achieve a prominent idea, emphasizing a certain emotional or enhance the rhythm of the purpose. In order to achieve the balance, symmetry and other effects of sentences, and strengthen the tone, momentum of the sentence, repeated and ranked methodsare often used in Chinese and English. However, when the repetitive part of the Chinese sentence is translated into English, it is often necessary to simplify, replace or omit the article so that the translation is cumbersome and procrastinating. For example, "The people fear notdeath; why threaten them with it?" Translator simplified as "The people fear notdeath; why threaten them with it?"

Cultural Dimension Adaptive Selection Conversion. The transformation of cultural dimension adaptive choice refers to the translation and interpretation of the connotation of bilingual culture in the process of translation. The translator should pay attention to the difference between the content and the nature of the culture of the original language and the target language, so as to make the adaptive choice and conversion for the same effect of the original culture of the readers with different cultural backgrounds.

Such as the idiom "beat swards to ploughs". It is very clever of translating it into "beat swards to ploughs". "beat swards to ploughs" means that the soldiers meet each other for the jade and silk, hoping to resolve the war into peace and friendship.

Communicative Dimension Adaptive Selection Conversion. The adaptive choice of communicative dimension refers to the adaptive choice of conversational interest in the process of translation. Some culture load words, if literal, the listener can not understand the meaning of the 
original language speaker, then you need to add explanatory translation when retaining the original language and cultural images.

For example: "A thousand sails pass by the wrecked ship; ten thousand saplings shoot up beyond the withered tree", At that time the translator translated it directly as "A thousand sails pass by the wrecked ship; ten thousand saplings shoot up beyond the withered tree", the author believes that it is necessary to make a further explanation in order to better make the listener understand the speaker's point of view.

\section{The Improvement of Chinese Culture-Loaded Words}

In view of the imbalance between the translation of English and Chinese cultural load words in the context of globalization and the inadequate transmission of Chinese cultural load words in the context of the target language, the ecological translation of the current Chinese cultural load words should improve the translation of the ecological environment and enhance the quality of translators two aspects.

To Improve the Ecological Environment of Translation. The improvement of the translation ecological environment will help the transmission of Chinese cultural load words. To improve the translation of the ecological environment mainly refers to the promotion of China's comprehensive national strength and the influence of Chinese in the world to expand the transmission of Chinese culture load words. Translation is a kind of cultural exchange mode with language as the tool. The ecological environment which has the greatest influence on the ecological translation of Chinese culture load words is the position of Chinese culture and its culture in the world language and culture ecosystem. In the final analysis, the status of language and culture in the world for different countries is determined by the economic, political, military and other forces. Therefore, the improvement of China's comprehensive national strength will bring about the rising of China's international status and the expansion of Chinese international influence. This will help the target readers to increase their understanding of the background knowledge of Chinese culture load words then promote thetransmission and acceptance in the context of translation target language.

To Enhance the Quality of Translators. Eco-translator argues that "the translator plays a central role in the process of translation and plays a leading role." The translations are closely related to the quality of the translator. As the subject and the center of translation, the translator's translation theory level, practical ability and personal temperament, artistic accomplishment and others will be reflected in the translation process and directly affect the expression of Chinese language culture loaded words. Therefore, the ecological translation of Chinese cultural words requires the translator to enhance the level of translation theory and practical ability. The improvement of translator 's quality mainly refers to the translator' $s$ translation theory level, practical ability and personal temperament, artistic accomplishment and so on which directly or indirectly affect the Chinese culture loaded word expression.

\section{Conclusion}

As China's political, economic and military strength continues to strengthen, we are increasingly frequent with the world. While the cultural loaded words are the inevitable problems in the interpretation of the conference, the translator can not be confined to literal translation. This paper attempt to analyze the interpretation of cultural - loaded words from the perspective of three dimensional transformation of ecological translation. On the one hand, this is an attempt to carry out translation activities from a new perspective, and a process from zero to one; on the other hand, this new attempt also allows the translator to remove the inherent experience, instinctive translation of the monotonous mode in the translation process, and make it into the multi-dimensional, rational level, which lead to get the best translation. 


\section{Acknowledgement}

Project funding: Jiangxi Province Humanities and Social Science Project (No.: YY162011) \& Nanchang Institute of Technology Youth Fund (No.: 2010SK027)

\section{References}

[1] Guo X F. On Translation Ecology and Eco-translatology: Research Objects,Methods and Trends[J]. Foreign Language Research, 2015.

[2] Tao X T. Study on Translational Ecological Environment in Ecological Translatology and Translation Ecology[J]. Northern Horticulture, 2014.

[3] Gao W W. International Publicity Translation from the Perspective of Language Ecology and Eco-translatology[J]. Journal of Huaihua University, 2011.

[4] Zhang L, Jin W. Eco-translatology and Its Three Ecological Dimensions-A Discussion with Prof.Hu Gengshen[J]. Journal of University of Shanghai for Science \& Technology, 2011.

[5] Zhang W. Study on the Development of English Translation of Chinese Classics from the Perspective of Eco-translatology[J]. 2017(icsste).

[6] Tao X T. Study on Translational Ecological Environment in Ecological Translatology and Translation Ecology[J]. Northern Horticulture, 2014.

[7]Chen S B, Zuo Y Z. A Research on Pun Translation from the Perspective of Eco-translatology[J]. Journal of Hunan First Normal University, 2013.

[8] Chen Y. A New Perspective for Eco-Translatology-On Paradigm Shift of Ecological Translation in Chinese-English Poetry Translation[J]. Foreign Language Education, 2015.

[9] Huang H, University H A. Study on some basic issues of translation theory from "meme"and "ecology"perspectives[J]. Journal of Changchun Institute of Technology, 2016.

[10]Fei-Fei X U. Developing Non-English Majors' Interpreting Competence: A Perspective of Eco-translatology[J]. Journal of Hunan First Normal University, 2016.

[11] Yu Z. Translation as adaptation and selection: a feminist case[J]. Perspectives Studies in Translatology, 2016:1-17.

[12] Chen J. On Similarities between Translation View of Reception Aesthetics and Eco-translatology[J]. Journal of Guangdong University of Foreign Studies, 2016. 